Case Reports
in Dermatology
Case Rep Dermatol 2021;13:474-480

DOI: $10.1159 / 000512708$
Published online: September 23, 2021

(C) 2021 The Author(s)

Published by S. Karger AG, Basel www.karger.com/cde

This article is licensed under the Creative Commons Attribution-NonCommercial 4.0 International License (CC BY-NC) (http://www.karger.com/Services/OpenAccessLicense). Usage and distribution for commercial purposes requires written permission.

\title{
A Case of Exfoliative Vesiculobullous Prurigo Pigmentosa Cured by Doxycycline and Topical Tacrolimus
}

\author{
Hoon Choi Choong Jae Kim Chan Ho Na Bong Seok Shin \\ Min Sung Kim \\ Department of Dermatology, Chosun University School of Medicine, Gwangju, Republic of \\ Korea
}

\section{Keywords}

Bullous lesion · Doxycycline · Exfoliative lesion · Prurigo pigmentosa - Topical tacrolimus

\begin{abstract}
Prurigo pigmentosa is a rare inflammatory skin disease characterized by an unexpected onset of diffuse erythematous papules and macules usually on the chest, neck, and back. These generally resolve, leaving reticular hyperpigmentation. Rarely, vesicular or bullous forms have been reported. We present a case of exfoliative vesiculobullous prurigo pigmentosa in a 13-yearold boy. He presented with symmetrical eruption of papules and vesicles on his back, neck, and chest in the last 10 days, causing pruritis and prickling sensation. Within a few days, the bullous lesions and all affected areas of the skin showed exfoliation. Histological study and clinical findings indicated the condition to be vesiculobullous prurigo pigmentosa with exfoliation. Treatment with doxycycline $200 \mathrm{mg} /$ day and topical tacrolimus ointment showed a good response. The lesions resolved, leaving a light-brown reticulated hyperpigmentation. In conclusion, this was a case of exfoliative vesiculobullous prurigo pigmentosa in an adolescent man successfully treated with doxycycline and topical tacrolimus as an effective and safe treatment option.




\section{Case Reports in Dermatology}

Case Rep Dermatol 2021;13:474-480

DOI: $10.1159 / 000512708$

C 2021 The Author(s). Published by S. Karger AG, Basel www.karger.com/cde

Choi et al.: A Case of Exfoliative Vesiculobullous Prurigo Pigmentosa

\section{Introduction}

Prurigo pigmentosa (PP) is a relatively rare skin disease in young adults, characterized by symmetrical erythematous papules and macules usually on the back, chest, and posterior part of the neck, accompanied by severe itching. These progress into confluent erythematous maculopapules, which heal, leaving behind reticulated and mottled hyperpigmentation. The disease occurs more frequently during spring and summer in young women and often recurs as well [1]. PP has various clinical features, but formation of vesicles or bullae is very rare [2]. To the best of our knowledge, the 13-year-old boy in our report is the youngest male person in the literature, with unusual and rare exfoliative vesiculobullous PP successfully treated with doxycycline and topical tacrolimus.

\section{Case Presentation}

A 13-year-old boy presented with a 10-day history of pruritic and tingling erythematous papules and macules on his back, chest, and neck. He was referred from the local hospital because the lesions were gradually increasing in size and number, with newer erythematous papules, vesicles, pustules, and bullae. The pruritus and pain were aggravating as well. His medical and family history was unremarkable. On physical examination, he was $171 \mathrm{~cm}$ tall and quite skinny with a weight of $50 \mathrm{~kg}$. The skin showed vesicles, pustules, and papules with an erythematous base on the back and nape, in a wedge-shaped distribution. The chest showed linear erythematous papules and vesicles extending from the center to the left shoulder (Fig. 1a, b). Laboratory examinations revealed a white blood cell count of $13,370 / \mathrm{mm}^{3}$ and an anti streptolysin O (ASLO) titer of $469.1 \mathrm{IU} / \mathrm{mL}$ (normal: 0-160). All other laboratory results - including a complete blood cell count, blood chemistry panel, liver function tests, and hematology tests including erythrocyte sedimentation rate/C-reactive protein, syphilis, electrocardiogram, chest X-ray, and urinalysis - were within the normal limits. A specimen for skin biopsy was taken from the vesicle on the middle of chest. The histology showed an intraepidermal vesicle, spongiosis, and perivascular inflammatory cell infiltration. Numerous neutrophils and lymphocytes, dyskeratotic cells, and eosinophils were observed in the vesicle and in the papillary dermis. The dermis showed edematous changes (Fig. 2). On immunofluorescence staining, C3, IgG, IgA, and IgM were negative.

The patient was admitted to the dermatology department for 10 days and administered doxycycline $200 \mathrm{mg} /$ day, methylprednisolone $40 \mathrm{mg} /$ day and antihistamines to control the acute-phase inflammation. Topical $0.1 \%$ tacrolimus ointment (Protopic ${ }^{\circledR}$ ) was used twice a day and propacetamol $2 \mathrm{~g}$ was administered for 10 days at 8-h intervals for pain control. Until the 3rd day of hospitalization, new vesicles and pustules continued to develop on the chest and back area. During dressing, the vesicles and bullae were punctured with a needle and all the skin lesions exfoliated over time (Fig. 1c, d). Later, the patient was discharged with improved skin symptoms without recurrence of vesicles and papules. At the time of discharge, the skin lesions on the back showed reepithelialization after exfoliation, leaving behind reticulated hyperpigmentation. The pruritus and pain almost ceased and only intermittent pruritus remained. At discharge, doxycycline $200 \mathrm{mg}$ /day, antihistamines, and $0.1 \%$ tacrolimus ointment were prescribed for 3 weeks. On subsequent follow-up, his skin lesions had almost healed and only some hyperpigmentation remained. At present, 12 months later, only slight pigmentation remains without recurrence.

\section{Karger'=}




\section{Case Reports in Dermatology}

Case Rep Dermatol 2021;13:474-480

DOI: $10.1159 / 000512708$

(c) 2021 The Author(s). Published by S. Karger AG, Basel www.karger.com/cde

Choi et al.: A Case of Exfoliative Vesiculobullous Prurigo Pigmentosa

\section{Discussion and Conclusion}

PP was first described by Nagashima in 1971, comprising erythematous plaques and papules accompanied by severe pruritus usually on the back, chest, and neck [3]. The disease occurs more frequently during spring and summer, and improves leaving behind reticular hyperpigmentation. More than 300 cases have been reported in Japan, 100 cases in Korea, and numerous cases in other countries, including Turkey and Europe. In English publications, the male-to-female ratio was reported as 1:4-1:6, and in Korean publications, the male-to-female ratio reported ranged from 1:2.4 to 1:3.6, with the prevalence being highest among young women in their late 10s and early 20s [4]. To date, studies on the Korean population have reported most cases among males from 17 to 24 years of age, with 3 cases reported among those above 50 years old $[5,6]$. Our patient was 13 years old, the youngest reported male patient in Korea. According to previous studies, males have a lower incidence than females, and most affected women are between the ages of 18 and 27 years, while in men the disease has been reported among those aged 17-64 years [7, 8]. In comparison, the youngest female affected with the disease was 11 years old, while the oldest was 37 years old and was the only female patient with PP above 30 years of age reported in Korea $[9,10]$. The disease seems to occur in women in their late 10s and in the 20s and rarely occurs in women above 30 years of age. In males, many cases have been reported among those in their 20s, but PP is also often seen in those in their 30s and above.

Clinically, PP comprises severe pruritic erythematous papules and occasionally papulovesicles that are symmetrical and typically affect the back, chest, and neck. Each papule merges into confluent plaques and patches, which disappear, leaving behind brown reticular hyperpigmentation. It usually takes several weeks before the erythematous papules and erythema become hyperpigmented. Relapses are seen in approximately $50 \%$ of those affected, and the duration of illness has been reported to be 6 months to 8 years [11]. Formation of vesicles or bullae is rare and is thought to be a result of vacuolar degeneration due to severe spongiosis and liquefaction of the basal cell layer [12]. Kim et al. [2] reported that 2 out of 50 patients with PP developed prominent vesicles, and English publications report the rate to be less than $10 \%$. Prominent bullous lesions are seen in about $5 \%$ of patients with PP. In our case, erythematous papules with erythema were seen 10 days before hospitalization, and vesicles and bullae developed a few days later. New pustules and vesicles in a wedge-shaped distribution were seen on the back and nape. The patient developed severe pain over time, which has not yet been reported for PP, although some patients have reported non-itching PP. Antihistamines and NSAIDs were hence prescribed.

The pathophysiology of PP is not yet understood. However, in Korea, many affected patients also reported weight loss, unlike those in other countries. Other factors suggested as possible triggers include clothing irritation, contact dermatitis, ketosis, pregnancy, diabetes, swimming, and sweating. Seasonal variations like spring and summer seem to be associated with sweating [13]. Although it was difficult to identify a clear causal relationship in this case, it is suspected that the association with sweat and a skinny body were the triggering factors based on the patient's history about warm weather leading to sweating on the chest and back, which in turn caused miliaria-like papules.

The histopathological findings of PP are nonspecific, but inflammatory cell infiltration, including neutrophils, spongiosis, ballooning degeneration, and necrotic keratinocytes, may be observed during the early stages of erythematous papules. In the fully developed stage with confluent erythematous plaques and papules, vesicles or pustules may be formed as a result

\section{Karger'=}




\section{Case Reports in Dermatology}

Case Rep Dermatol 2021;13:474-480

DOI: $10.1159 / 000512708$

C 2021 The Author(s). Published by S. Karger AG, Basel www.karger.com/cde

Choi et al.: A Case of Exfoliative Vesiculobullous Prurigo Pigmentosa

of significant lichenoid infiltration of lymphocytes and eosinophils in the dermis; hyperkeratosis, dyskeratosis, and spongiosis are also more predominant. In the late stage of brown hyperpigmentation, sparse lymphocytes and melanophages, parakeratosis, and epidermal hyperplasia are seen in the upper dermis [11]. Both clinical and histopathologic features are necessary to diagnose this inflammatory disease. In this case, the vesiculobullae in the epidermis were clearly associated with inflammation and spongiosis. In addition, when the inflammation is severe and blisters are large, the skin of the lesions might develop exfoliation as in our case.

Differential diagnoses of PP include pigmented contact dermatitis, confluent and reticulated papillomatosis, erythema dyschromicum perstans, Kaposi's varicelliform eruption, and acute lupus erythematosus. If there are accompanying bullous lesions like in our case, they might resemble dermatitis herpetiformis, contact dermatitis, bullous lupus erythematosus, photodermatitis with blisters, or linear IgA disease. In young adult women with clinical features of pruritic erythematous papules on the back or chest during spring and summer, PP should be considered as a differential diagnosis based on clinical manifestations, history, and histological findings.

For the treatment of PP, dapsone was mainly used before 2000. Later, minocycline was used as a treatment of choice, with less adverse effects and a longer period of remission. Minocycline and doxycycline are semi-synthetic tetracyclines that inhibit the proliferation of lymphocytes, neutrophil migration, chemotaxis, and phospholipase A2, and inhibit the expression of cytokines and chemokines that regulate the differentiation and activation of leukocytes, which leads to anti-inflammatory and immunomodulatory effects [14]. The anti-inflammatory effects of minocycline and doxycycline have not been compared, but both showed good outcomes in many cases of PP. In this case, there was disease stabilization and prevention of new lesions after administration of doxycycline. To reduce pruritus and inflammation, $0.1 \%$ tacrolimus ointment (Protopic ${ }^{\circledR}$ ) was used as a topical preparation, and it seems to have an effect on itching and inflammation. Tacrolimus ointment binds to FK-506-binding protein, a protein in T lymphocytes, inhibits calcineurin activity and the function of antigen-cognitive T lymphocytes, and interferes with the activation of NFAT (nuclear factor of activated T cells). By inhibiting the production of IL- 2 to IL-5, IFN- $\gamma$, and TNF- $\alpha$, among others, it exhibits an immune response and inhibitory effects [15]. It is thought that the suppression of T-cell activation by tacrolimus inhibits the inflammatory response of the lesions. It is reported to be effective in atopic dermatitis, vitiligo, psoriasis, lichen planus and many nonspecific inflammatory skin diseases.

Based on the clinical and histological findings, we diagnosed the case as exfoliative vesiculobullous PP. It was characterized by severe pruritus and pain, with exfoliation due to severe erythematous vesiculobullous papules. Treatment of PP with topical tacrolimus and doxycycline has not been reported so far. Therefore, the use of tacrolimus ointment as a topical agent in combination with minocycline or doxycycline in PP might be a new therapeutic alternative to improve the symptoms and clinical features of the lesions. However, comparisons between groups with large numbers of patients are necessary to study the outcomes of topical tacrolimus use. This case of severe PP with vesicles and bullae causing pain and exfoliation is the first ever reported in a young boy of 13 years, which makes it interesting and an important contribution to the literature.

\section{Karger'=}




\section{Case Reports in Dermatology}

\section{Statement of Ethics}

The patient and his parents gave written informed consent for publication of his case (including publication of images). The study was done according to the Declaration of Helsinki.

\section{Conflict of Interest Statement}

The authors have no conflicts of interest to declare.

\section{Funding Sources}

No funding was received.

\section{Author Contributions}

H. Choi and C.J. Kim collected the data and wrote the initial manuscript draft. C.H. Na wrote the pathologic description and manuscript. B.S. Shin wrote the manuscript and did language editing. M.S. Kim evaluated and revised the manuscript and is the corresponding author. All authors provided critical feedback and contributed to the final version of the manuscript.

\section{References}

1 Nagashima M. Prurigo pigmentosa - clinical observations of our 14 cases. J Dermatol. 1978 Apr;5(2):61-7.

2 Kim JK, Chung WK, Chang SE, Ko JY, Lee JH, Won CH, et al. Prurigo pigmentosa: clinicopathological study and analysis of 50 cases in Korea. J Dermatol. 2012 Nov;39(11):891-7.

3 Nagashima M, Ohshiro A, Shimizu N. A peculiar pruriginous dermatosis with gross reticular pigmentation. Jpn J Dermatol. 1971;81:78-91.

4 Kim JE, Song HJ, Oh CH. A case of vesicular prurigo pigmentosa. Korean J Dermatol. 2008;46:281-4.

5 Jeong JS, Lee JY, Kim MH, Seo YJ, Yoon TY. A clinical and histopathological study of 27 cases of prurigo pigmentosa. Korean J Dermatol. 2010;48:573-81.

6 Shin JW, Lee SY, Lee JS, Whang KU, Park YL, Lee HK. Prurigo pigmentosa in Korea: clinicopathological study. Int J Dermatol. 2012 Feb;51(2):152-7.

7 Kwon HJ, Kim MY, Kim HO, Park YM. Two cases of prurigo pigmentosa in atopic patients. J Dermatol. 2006 Aug;33(8):579-82.

8 Kim MH, Choi YW, Choi HY, Myung KB. Prurigo pigmentosa from contact allergy to chrome in detergent. Contact Dermat. 2001 May;44(5):289-92.

9 Sung KH, Lee SK. Prurigo pigmentosa: clinicopathologic study and expression of ICAM-1. Ann Dermatol. 2004;16(4):153-62.

10 Chun YS, Chang SN, Han SK, Choi ES, Chun SI, Park WH. Prurigo pigmentosa: a report of 5 cases with a review of the Korean literature. Ann Dermatol. 1998;10(2):132-7.

11 Böer A, Misago N, Wolter M, Kiryu H, Wang XD, Ackerman AB. Prurigo pigmentosa: a distinctive inflammatory disease of the skin. Am J Dermatopathol. 2003 Apr;25(2):117-29.

12 Matsumoto C, Kinoshita M, Baba S, Suzuki H, Kanematsu S, Kanematsu N. Vesicular prurigo pigmentosa cured by minocycline. J Eur Acad Dermatol Venereol. 2001 Jul;15(4):354-6.

13 Hyun DJ, Lee HJ, Kim DH, Yoon MS. Bullous Prurigo Pigmentosa with Eosinophilia. Korean J Dermatol. 2017;55(3):217-9.

14 Leite LM, Carvalho AG, Ferreira PL, Pessoa IX, Gonçalves DO, Lopes AA, et al. Anti-inflammatory properties of doxycycline and minocycline in experimental models: an in vivo and in vitro comparative study. Inflammopharmacology. 2011 Apr;19(2):99-110.

\section{Karger'=}




\section{Case Reports in Dermatology}

\begin{tabular}{l|l}
\hline Case Rep Dermatol 2021;13:474-480 \\
\hline DOI: 10.1159/000512708 & $\begin{array}{l}\text { (c) 2021 The Author(s). Published by S. Karger AG, Basel } \\
\text { www.karger.com/cde }\end{array}$ \\
\hline
\end{tabular}

Choi et al.: A Case of Exfoliative Vesiculobullous Prurigo Pigmentosa

15 Kim MR, Lee SE, Kim SC. Successful Treatment of Localized Epidermolysis Bullosa Acquisita with Low-Dose Dapsone and Topical Tacrolimus. Korean J Dermatol. 2009;47(9):1090-3.
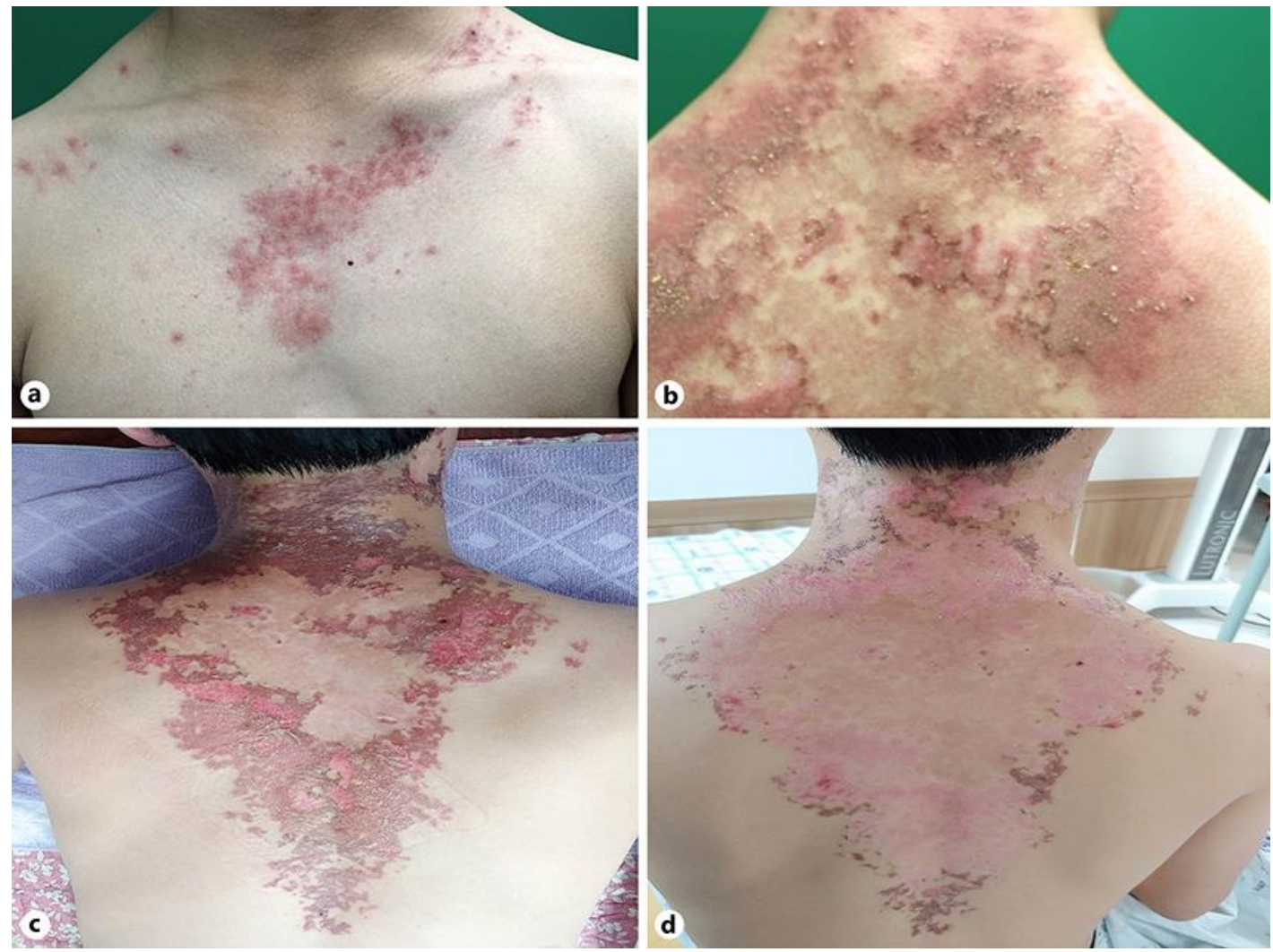

Fig. 1. a Multiple localized, grouped erythematous papules and vesicles on the upper chest on the day of admission. b Multiple erythematous confluent papules, vesicles, and pustules with reticular hyperpigmentation in a wedge-shaped distribution on the upper back on the day of admission. c Vesicular lesions intermingled with erythematous papules and brownish patches with exfoliative and erosive lesions on the upper back on the 4 th day of treatment. $\mathbf{d}$ Reticulated brownish pigmentation and pinkish skin lesions after complete desquamation on the 8th day of treatment. 


\section{Case Reports in Dermatology}
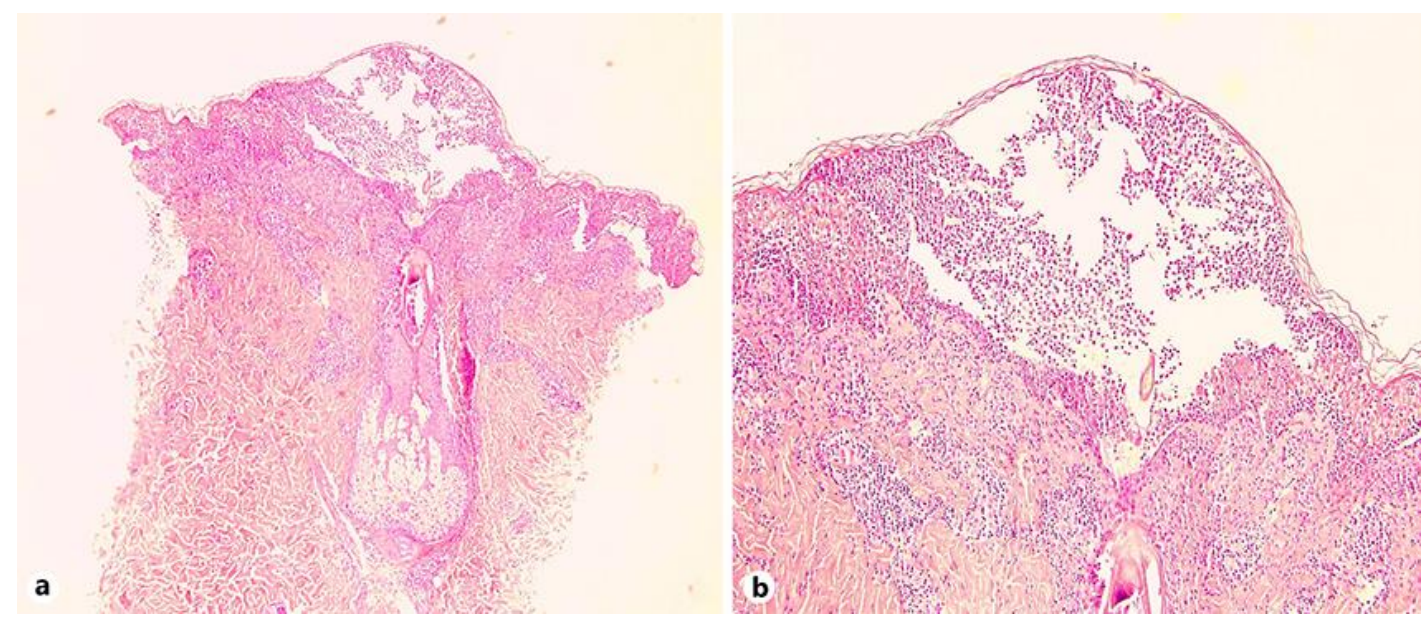

Fig. 2. Histopathological findings. a Intraepidermal vesicle with a number of neutrophils, eosinophils, and lymphocytes densely infiltrating the epidermis and papillary dermis. H\&E. $\times 40$. $\mathbf{b}$ Intraepidermal vesicle with a number of neutrophils, eosinophils, and lymphocytes. H\&E. $\times 100$. 